\title{
GÊNEROS COMO AÇÕES RECORRENTES: análise de materiais didáticos de PLE
}

\author{
Denise Barros Weiss \\ Universidade Federal de Juiz de Fora \\ Mariana Camargo Bessa \\ Universidade Federal de Juiz de Fora \\ Luciana Damasceno Kreutzfeld \\ Universidade Federal de Juiz de Fora
}

\section{RESUMO}

O objetivo deste artigo é analisar o modo como os gêneros textuais são explorados em dois conjuntos de materiais didáticos preparados para públicos específicos. O primeiro material analisado foi elaborado pela autora Denise Barros Weiss, professora da Universidade Federal de Juiz de Fora, e utilizado em um Curso de Português como Língua Estrangeira para alunos de nível intermediário. Já o segundo material analisado foi utilizado em um curso de português como língua estrangeira, ocorrido no Instituto Federal de Educação, Ciência e Tecnologia do Sudeste de Minas Gerais (IF Sudeste) em 2016. Empregamos a definição de gêneros como ações sociais tipificadas e recorrentes, sustentada por autores como Miller (1984) e Bazerman (1994). Além disso, a definição do conceito de texto sustentada por Bronckart (2012) e as noções de "propósito comunicativo» e «comunidade discursiva» elaboradas por Swales (1990) serviram de apoio à análise dos dados. Os conceitos teóricos empregados puderam iluminar o modo como analisamos os exemplos de atividades. Pretendemos, com este trabalho, demonstrar que, por meio da exploração dos usos de diversos gêneros textuais, os papéis sociais e as ações desempenhadas pelos falantes são enfatizados durante o ensino de uma língua estrangeira.

PALAVRAS-CHAVE: Gênero. Ação Social. Português como Língua Estrangeira. Material Didático. 


\section{Introdução}

Segundo Bronckart (2012, p. 103), “a apropriação dos gêneros é um mecanismo fundamental de socialização, de inserção prática nas atividades comunicativas humanas". Tornamo-nos capazes de compreender as interações sociais por meio do auxílio desses gêneros, os quais refletem a relação entre linguagem e realidade social (BAZERMAN, 2005 apud TOSATTI, 2009, p. 2). Devido ao papel extremamente relevante que ocupa na vida dos usuários da língua, o gênero tem sido cada vez mais enfatizado nos estudos a respeito do ensino de língua materna e língua estrangeira, e no interesse acerca do modo como é explorado em contexto. Considerando o lugar privilegiado assumido pelos gêneros no dia a dia de um estudante nativo e no de um estrangeiro e a influência que exercem no processo de inserção desses alunos na língua-alvo, o objetivo principal deste artigo é analisar como esses gêneros textuais são explorados em um livro didático de Português como Língua Estrangeira. Partindo da noção de gênero como uma ação social, isto é, como um modo de agir socialmente (MILLER, 1984,1994; BAZERMAN, 1994); das definições de "propósito comunicativo" e "comunidade discursiva" sustentadas por Swales (1990) e de alguns conceitos sustentados por Bronckart (2012) a respeito das coordenadas de tempo e espaço estabelecidas pelos gêneros, o artigo está dividido em cinco seções: a primeira consiste na introdução do trabalho e a segunda parte diz respeito à fundamentação teórica. $\mathrm{Na}$ terceira, discutimos acerca da aplicabilidade dos gêneros textuais em um livro didático de PLE. Na quarta e na quinta seção, apresentaremos os resultados da análise dos exemplos de atividades retiradas dos materiais escolhido. Já na sexta e última parte do trabalho, são apresentadas as conclusões finais a respeito dos dados analisados.

\section{Fundamentação Teórica}

De acordo com Miller (1984), pesquisadora norte-americana e professora de Retórica e Comunicação Técnica na Universidade Estadual da Carolina do Norte (EUA), os gêneros se referem a uma "categoria convencional do discurso baseada na tipificação em larga-escala de uma ação retórica, e, como ação, esses adquirem significado a partir das situações surgidas/ocorridas no interior de um determinado contexto social" (MILLER, 1984, p. 163, tradução nossa). Miller (1984) afirma, em seu artigo "Genre as Social Action", que a sua definição de gênero está baseada nas 
convenções do discurso estabelecidas pela sociedade a fim de que os indivíduos possam agir conjuntamente, isto é, para possibilitar ações coletivas. Partindo da noção de gênero como "ação retórica tipificada" (MILLER, 1994, p. 24), a autora defende que os gêneros devem ser vistos como uma resposta aos eventos e situações com as quais nos deparamos regularmente ao interagirmos socialmente. Miller afirma que, por ser definido como uma ação recorrente, o gênero deve ser visto como um reflexo das experiências pelas quais os usuários passam, e que são materializadas nos textos. Assim, segundo ela, "compreender os gêneros socialmente pode nos ajudar a explicar como encontramos, interpretamos, reagimos a e criamos certos textos" (MILLER, 1984 apud CARVALHO, 2005, p. 133).

A autora utiliza a expressão "retórica" em sua definição de gênero a fim de salientar a importância dos propósitos e motivações dos usuários, sem deixar de enfatizar as especificidades do contexto social nos quais operam. De acordo com ela, "o conjunto de gêneros representa um sistema de ações e interações que possuem funções e localizações sociais específicas, assim como um valor ou função recorrente ou repetida" (MILLER, 1994, p. 70, tradução nossa). Faz-se necessária, portanto, a compreensão da relação entre as ações particulares de agentes individuais e, por outro lado, a influência abstrata e distintiva da sociedade, das instituições e da cultura (MILLER, 1994, p. 70). Através do trabalho do sociólogo inglês Giddens (1984) acerca das noções de "sistemas" e "estruturas", o entendimento dessa relação se torna mais claro. Giddens (1984 apud CARVALHO, 2005, p. 134) afirma que

as atividades sociais humanas, assim como alguns elementos auto-reprodutivos na natureza, são recorrentes. Isto é, não são trazidas à existência por atores sociais, mas são continuamente recriadas por eles mediante os próprios meios pelos quais se exprimem como atores. Em e por meio de suas atividades os agentes reproduzem as condições que fazem com que essas atividades sejam possíveis.

Para o autor, os sistemas "são formados por padrões recorrentes de interação e ação"(CARVALHO, 2005, p. 134). Já as estruturas "são constituídas por regras e recursos que orientam a manutenção e reprodução dos sistemas".

Carvalho se aproxima da ideia proposta por Giddens ao afirmar que "atores sociais criam recorrência em suas ações ao reproduzirem aspectos estruturais das instituições, ao utilizarem estruturas disponíveis como mediadoras de suas ações e, portanto, ao produzirem novamente essas 
estruturas como resultados virtuais, os quais estão disponíveis para uso e interpretação (MILLER, 1994, p. 71, tradução nossa). O gênero, segundo ela, é visto como o aspecto da comunicação situada que está sujeito à reprodução, isto é, que pode se manifestar em mais de um contexto histórico e social. Por ter a capacidade de estruturar as ações sociais (CARVALHO, 2005, p. 135), este é visto como o elo entre os espaços público e privado, entre a comunidade e o indivíduo.

Assim como Miller, Bazerman (1994) também sustenta a perspectiva de gênero como ação social, “observando as regularidades nas propriedades das situações recorrentes (dá atenção às intenções sociais nelas reconhecidas), que dão origem a recorrências na forma e no conteúdo do ato de comunicação" (CARVALHO, 2005, p. 135). Segundo o autor, para que tenhamos um conhecimento mais aprofundado acerca dos gêneros, é preciso que esses sejam concebidos como "fenômenos de reconhecimento psicossocial que são parte de processos de atividades socialmente organizadas" (BAZERMAN, 2005, p. 32). De acordo com o seu ponto de vista,

Gêneros são tão-somente os tipos que as pessoas reconhecem como sendo usados por elas próprias e pelos outros. Gêneros são o que nós acreditamos que eles sejam. Isto é, são fatos sociais sobre os tipos de atos de fala que as pessoas podem realizar e sobre os modos como elas os realizam. Gêneros emergem nos processos sociais em que pessoas tentam compreender umas às outras suficientemente bem para coordenar atividades e compartilhar significados com vistas a seus propósitos práticos. (BAZERMAN, 2005, p. 32).

Assim, Bazerman ressalta a relevância dos usuários na identificação do que pode ser tido como recorrente. Para o autor, os gêneros estão intimamente relacionados às interações sociais e condicionados ao reconhecimento que os participantes do discurso fazem deles.

Nas visões de Miller e Bazerman, ambos influenciados pela orientação norte-americana de estudos dos gêneros, termos como "recorrência" e "ação social" são tidos como noções-chave na definição de um gênero textual. Miller afirma que a função social de um texto está relacionada ao grupo social que o produz, e se todos os textos convencem, todos eles têm algo de retórico, isto é, querem modificar algo no outro. Conclui-se que, de acordo com Miller (1994), o gênero está ligado às categorias convencionais do discurso, já que deriva de ações retóricas tipificadas; "é interpretável por meio das regras que o regulam; é distinto, mas é uma fusão entre forma e substância" (CARVALHO, 2005, p. 134), 
e, além disso, pode-se dizer que está envolvido no processo de organização e instituição da cultura.

\section{A aplicabilidade dos gêneros textuais em mate- riais didáticos de PLE}

Já é ponto pacífico que o livro didático (LD) é visto como o material teórico mais frequente e mais utilizado por professores e estudantes em aulas tanto de língua materna quanto de língua estrangeira. Diante do papel de extrema importância que assume no contexto escolar, é necessário que esse material didático seja analisado minuciosamente e criticamente antes de ser empregado pelo professor, já que, a partir dele, diversos gêneros textuais serão apresentados aos alunos. Partindo da noção de gênero como ação, ao terem contato com os gêneros textuais presentes em um LD, os alunos são levados a compreender e vislumbrar as formas de ação de uma sociedade, as quais estão materializadas na linguagem.

Os professores de língua estrangeira, assim como os de língua materna, devem fazer com que seus alunos estejam aptos a entenderem e produzirem gêneros de forma autônoma e consciente, para que eles possam circular pelas mais diversas realidades e esferas de atividade humana. Pensando nisso, é dever dos autores de livros didáticos pensar nas mais diversas situações de uso da língua, a fim de que esses materiais contemplem os mais variados gêneros. Entretanto, essas realidades sociais estão em constante renovação, o que gera uma constante transformação dos gêneros também. Assim, é visível a dificuldade de se definir quais gêneros são mais adequados aos livros, devido ao fato de que eles estabelecem as coordenadas de tempo e espaço das formas mais variadas possíveis, como afirma Bronckart (2012).

Bronckart (2012) analisa os textos de acordo com os tipos de discurso, isto é, como "formas específicas de semiotização ou de colocação em discurso" (BRONCKART, 2012, p. 138), que se encontram numa espécie de "intertexto", de um depósito universal. Este depósito se assemelha à tecnologia de armazenamento em nuvem, isto é, aos locais na internet em que todo tipo de informação pode ser guardada e mantida em segurança. Assim como esse novo sistema tecnológico conhecido por "nuvem" está em constante mudança à medida que as informações armazenadas mudam, esse intertexto também está em permanente construção. Assim, segundo Bronckart (2012, p. 137), 
os textos são produtos da atividade de linguagem em funcionamento permanente nas formações sociais: em função de seus objetivos, interesses e questões específicas, essas formações elaboram diferentes espécies de textos, que apresentam características relativamente estáveis (justificando-se que sejam chamadas de gêneros textuais) e que ficam disponíveis no intertexto como modelos indexados, para os contemporâneos e para as gerações posteriores.

De acordo com o autor, toda vez que escrevemos um texto, desenhamos uma nova realidade, já que o conteúdo textual não é uma verdade factual, mas uma das diversas possíveis apreensões dessa realidade imprecisa. Com isso, ao produzir um texto, o usuário da língua deve estar atento à ocasião em que escreve, isto é, aos mundos em que está inserido. Nessa produção, o produtor deve estar atento ao mundo físico em que se encontra, isto é, ao local em que o texto é escrito; ao mundo social, ou à posição social em que ele está inserido e ao mundo subjetivo, ou seja, à situação pessoal dele. Essa complexidade na produção de um gênero demonstra que a coordenada (espaço-tempo) deste é forçosamente diferente da realidade. Há gêneros textuais completamente desgarrados do mundo físico, assim como há aqueles que, de um dia para o outro, podem perder o sentido, como as piadas e charges, que estão coladas na realidade social. Assim, pelo fato dos gêneros estabelecerem as coordenadas de espaço e tempo de diferentes maneiras, é inevitável o questionamento acerca de quais gêneros são mais adequados aos livros: os que estão agarrados ao mundo físico ou aqueles cujas coordenadas estão abertas.

Além de estarem condicionados à coordenada de espaço-tempo, os gêneros também estão sujeitos ao «propósito comunicativo» e à «comunidade discursiva», noções desenvolvidas pelo linguista britânico Swales (1990) e fundamentais para a análise crítica do livro didático. Autor da obra «Genre analysis: English in academic and research settings», Swales (1990 citado por SILVA, 2005, p. 2 - 3) afirma que

Um gênero compreende uma classe de eventos comunicativos, cujos membros compartilham os mesmos propósitos comunicativos. Tais propósitos são reconhecidos pelos membros especialistas da comunidade discursiva de origem e, portanto, constituem o conjunto de razões (rationale) para o gênero. Essas razões moldam a estrutura esquemática do discurso e influenciam e impõem limites à escolha de conteúdo e de estilo.

Portanto, é por meio dos propósitos que os gêneros são estruturados e identificados pelos membros da comunidade na qual são empregados. 
O conceito de comunidade, a qual é formada por indivíduos que compartilham conhecimentos acerca das regularidades de um gênero específico, é visto como complexo e de difícil definição, por conta da multiplicidade de propósitos existentes dentro de uma única comunidade. Esta pode ser vista como uma espiral, pois engloba tanto os indivíduos mais envolvidos com os mundos discursivos (os mundos relacionados à produção de textos) mais canônicos daquela comunidade quanto aqueles que ocupam as partes mais periféricas dessa espiral. Assim, pode-se afirmar que pertencemos a diversas comunidades discursivas, e, quanto mais heterogêneas essas forem, mais diverso será o entendimento de um gênero.

\section{Análise de gêneros textuais do material Português para Estrangeiros 11}

Os professores de língua estrangeira têm como objetivo/foco o desenvolvimento de propostas de atividades que contribuam para a ampliação dos níveis de proficiência dos estudantes na língua-alvo. De acordo com Widdowson (1991) a definição do termo proficiência não se atém somente às capacidades de leitura e escrita, à fala e à compreensão das orações nessa língua, mas

significa também saber utilizar essas orações de modo a conseguir o efeito comunicativo desejado. Sendo assim, o que um falante precisa para ser proficiente não é somente conhecer o sistema abstrato da língua, mas saber como usá-la adequadamente em determinada situação (TOSATTI, 2015, p. 32).

Assim, pode-se dizer que este é um conceito relativo, já que o nível de proficiência de um falante depende do quão proficiente é o outro com o qual ele interage e do contexto em que a comunicação se desenvolve.

Para que os estudantes compreendam o funcionamento de uma língua, cabe ao professor fornecer condições para que eles, de forma autônoma e crítica, construam seu próprio conhecimento. O livro didático, ferramenta básica no aprendizado de uma LE, faz parte dessas condições fornecidas pelos professores para que o processo de aprendizagem dos estudantes ocorra de forma autônoma e consciente. Devido ao papel que esses livros ocupam na rotina escolar e ao aumento do número de publicações de materiais didáticos voltados para os aprendizes de Português como língua estrangeira, foram analisadas no presente artigo propostas de atividades baseadas no emprego de diferentes gêneros textuais. Os exercícios foram retirados do material didático Português para Estrangeiros 
II - Curso Intermediário, elaborado pela Professora Denise Barros Weiss que atua como professora adjunta na Universidade Federal de Juiz de Fora, na área de Linguística com ênfase em Português como Língua Estrangeira. A fim de observarmos como os gêneros são explorados nesse livro, analisaremos o propósito comunicativo de cada um dos exemplos, a(s) comunidade(s) discursiva(s) a quem esses se dirigem e as ações retóricas tipificadas e recorrentes desempenhadas através da exploração desses gêneros.

A primeira atividade a ser analisada (Figura 1: Português para Estrangeiros II - versão 2015) explora o uso do gênero textual tirinha:

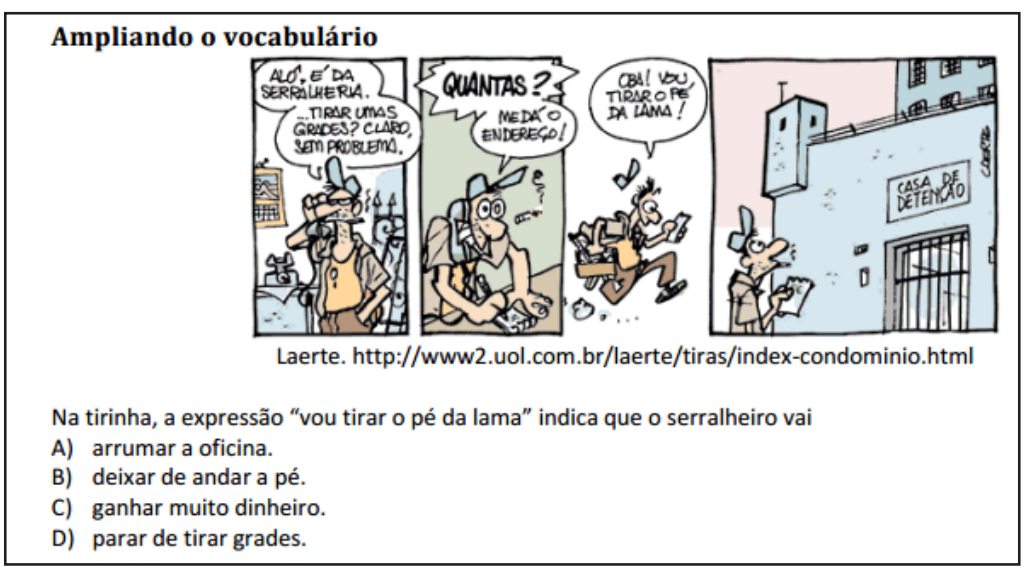

Figura 1: Português para Estrangeiros II - versão 2015.

Fonte: WEISS, 2015, p. 34.

As tirinhas têm como propósito comunicativo despertar humor, isto é, proporcionar entretenimento ao leitor. Essas são compostas tanto pela linguagem verbal quanto pela não-verbal, e só podem ser compreendidas de forma mais aprofundada a partir de uma leitura crítica de ambas as semioses/linguagens. Apesar do público infanto-juvenil representar a comunidade discursiva que mais lê tirinhas, este gênero também está presente no dia a dia de adultos que apreciam sua principal característica - o humor. Por meio de seu caráter humorístico e muitas vezes sarcástico, o gênero tirinha transmite conteúdos diversificados da atualidade, o que reforça a importância da adoção deste no contexto escolar.

A escolha da tirinha em questão se justifica pelo fato de que, além do humor e do tema da atualidade, há também o emprego da expressão popular 
"vou tirar o pé da lama". No contexto de uma sala de aula de Português como LE, expressões do tipo devem ser exploradas a fim de que o aluno compreenda quais os significados e os contextos de uso dessas, assim como os fatos históricos e sociais que ocasionaram o surgimento de certas expressões populares Assim, além de explorar temas como a realidade do sistema carcerário brasileiro e do mercado de trabalho, por exemplo, o professor também pode, a partir dessa tirinha, apresentar aos estudantes uma nova expressão da língua-alvo que pode vir a ser utilizada por eles em algum evento de uso da língua.

A Figura 2 exemplifica o modo como o gênero reportagem pode ser explorado em uma proposta de atividade presente em um material didático de PLE:

\section{UNIDADE 6 \\ REVENDO OS TEMPOS VERBAIS: OS TEMPOS DO IMPERATIVO E DO SUBJUNTIVO A globalização da culinária}

A gastronomia pode servir de critério para as relações do povo brasileiro com as palavras estrangeiras

John Robert Schmitz

O vocábulo "gastronoglobalização" é, por óbvio, a fusão das palavras "gastronomia" e "globalização" A globalização é um fenômeno considerado benéfico para alguns e problemático para outros. Faço uso do neologismo para referir-me à importação e exportação ou à troca de "comes e bebes" entre os diferentes países neste mundo cada vez mais interligado.

Nesta segunda década do século 21 , quem viaja pelo mundo e se hospeda em hotéis ou frequenta restaurantes, cantinas e lanchonetes em Londres, Tóquio ou Paris não deixa de notar nos cardápios palavras em pleno português, como "feijoada", "caipirinha", "caipiroska" e "guaraná". O que é agradável ao paladar sempre circula pelo mundo. $\mathrm{O}$ tomate, $\mathrm{o}$ milho, a batata e o chocolate são originários do continente americano, mas presentes em cozinhas, alpendres, supermercados e quitandas de toda parte. $\mathrm{O}$ prato de origem húngara gulyás (grafado "gulache" em português) e o "estrogonofe" são apreciados no mundo inteiro. Os brasileiros que vivem no exterior não precisam esperar o retorno para tomar suas caipirinhas.

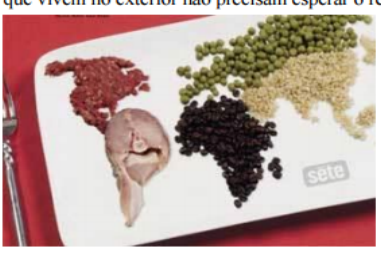

Quem visita Curitiba não demora a conhecer a iguaria de origem polonesa "pieroque" ou "pirogue", tipo de pastel cozido à base de massa, levedada com diferentes recheios. Um estrangeiro que conhece o Nordeste bem pode descobrir a "cartola", sobremesa de banana fatiada, coberta de queijo, canela e açúcar. Quem anda pelas ruas de Manaus encontra barracas de "tacacá", uma sopa de mandioca, camarões, molho de tucupi e outras especiarias.

Pode ser que a cartola e o tacacá um dia apareçam no estrangeiro. A internet apresenta páginas com receitas de pirogues, cartolas e tacacás em vários idiomas. Alguns

visitantes ao Brasil vão se lembrar dos vocábulos, o que é meio caminho andado para fixar a palavra no exterior. Bons candidatos são o vatapá e o acarajé.

\section{Receitas}

No Brasil, é curioso ver que quem reclama de vocábulos como delivery e deletar (do inglês "delete" pelo latim deletum, do verbo delere) não implica com as palavras de origem japonesa que aparecem em cardápios, como temaki, sushi, guioza, teppanyaki, shitake e sashimi. De fato, a cultura alimentícia japonesa é globalizada, segundo o professor Isao Kumakura, docente do Museu Nacional de Etnologia no Japão (The Globalization of Japanese Food Culture).

A comida italiana está presente no Brasil há muito tempo, mas o avanço de redes nacionais de supermercados estimulou no pais a distribuição de caixas e pacotes de diferentes tipos de massas, com nomes (em italiano) pitorescos para nossos padrões, com grafia de origem: farfalle (borboletas), orecchiette (orelhas pequenas), vermicelli (pequenas minhocas) e fusilli (parafusos). Ninguém se queixa da presença desses vocábulos nem os considera ameaças à sobrevivência do português.

Diria que problemas políticos e ideológicos relacionados a palavras de origem estrangeira desaparecem quando se trata das delícias da mesa. O estômago "fala" mais alto. É verdade que há 50 anos nem havia no Brasil as redes de comidas rápidas americana, árabe, italiana, chinesa ou japonesa. A globalização possibilitou a inserção de diferentes cuisines no pais. O resultado é que a alimentação ficou mais variada e, graças à criatividade dos chefes e à engenharia de alimentos, mais saborosa. Pois temos suflês e fricassés de legumes e verduras e frappés, mousse e ganaches. Outro resultado é o aumento no número 
de palavras em português, que exige registro de novas palavras nos dicionários. Quem não sabe a diferença entre sashimi, e sushi, ou entre burrito, taco e nacho, precisa de orientação.

John Robert Schmitz é professor do Departamento de Linguística Aplicada (IEL), da Universidade Estadual de Campinas (Unicamp) http://revistalingua.uol.com.br/textos/78/a-globalizacao-da-culinaria-255260-1.asp

Você já comeu alguma das comidas tipicas citadas na reportagem em seu pais de origem? Se comeu, qual foi?

Você encontra comidas típicas do seu pais aqui no Brasil? Elas lhe parecem semelhantes ou diferentes das que costuma comer lá?

Figura 2: Português para Estrangeiros II - versão 2015.

Fonte: WEISS, 2015, p. 48.

O propósito comunicativo do gênero reportagem é transmitir informações a respeito de um determinado tema ou assunto. A partir desse gênero textual, são explorados acontecimentos sociais, políticos e culturais diversificados, a fim de que o interesse de um público bastante múltiplo (de uma comunidade discursiva ampla) seja atendido. Percebe-se que, a partir da reportagem "A globalização da culinária", o professor pode rever alguns tempos verbais já trabalhados em sala, como o subjuntivo e o imperativo; levar os alunos a compreenderem e interpretarem o texto através das perguntas e, além disso, discutir com os estudantes acerca dos traços culturais do Brasil e dos seus países de origem, para que, por meio dessa comparação, eles compreendam que as culturas não estão dispostas hierarquicamente, isto é, que não há uma cultura superior ou inferior, mas sim diferente. O professor pode destacar também as diferenças existentes entre o gênero notícia e reportagem a partir dessa atividade, já que ambos são bastante utilizados no dia a dia dos alunos, isto é, estão em constante circulação.

Na Figura 3, há outro exemplo de uma atividade que explora o uso de um gênero empregado constantemente pelos alunos: 
Eu vi na Internet...

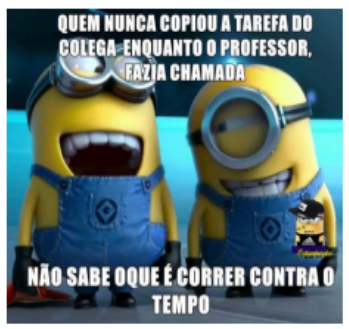

Sua vez... crie o seu próprio quadrinho, usando a expressão

"Quem nunca..."

Figura 3: Português para Estrangeiros II - versão 2015.

Fonte: WEISS, 2015, p. 48.

O nome atribuído a esse gênero multimodal surgiu em 1976, a partir da publicação do livro "The Selfish Gene" (O Gene Egoísta), escrito por Richard Dawkins. Este estudioso se baseou na teoria da evolução natural de Darwin para criar o pressuposto teórico da memética, em que o termo "meme" está relacionado ao gene pelo fato de que, enquanto este é definido como um componente orgânico, uma representação biológica do ser humano, aquele é visto como seu correspondente cultural e social. Assim, o meme seria "uma unidade de transmissão cultural, ou uma unidade de imitação" (DAWKINS, 2007 citado por SOUZA, 2014, p. 2).

No contexto digital, o gênero "meme" está relacionado "a tudo que se propaga, ou ainda se espalha aleatoriamente na Internet, em especial, fragmentos com algum conteúdo humorístico (SOUZA, 2013, p. 127). Os "memes", comumente falando, têm como propósito comunicativo o entretenimento dos usuários das redes sociais, e transmite conteúdos da atualidade. Segundo Erickson (1997 citado por MARCUSCHI, 2008, p. 198), "a interação online tem o potencial de acelerar enormemente a evolução dos gêneros". Apesar de ser um gênero cujas coordenadas de espaço-tempo são abertas, este deve ser explorado pelo professor devido à sua ampla circulação no meio digital e, consequentemente, na vida dos estudantes. Na atividade em questão, em que há a presença dos personagens minions do filme "Meu malvado favorito" (no original, Despicable $m e$ ), além de terem contato com esse meme, os estudantes também terão a oportunidade de produzir um de forma autônoma, a fim de que compreendam a estrutura e o funcionamento desse gênero. A partir dessa proposta de atividade, o professor estimula a criatividade dos alunos, e, além disso, 
abre portas para o entendimento do modo como funciona um gênero com o qual eles têm tanto contato.

\section{Análise de gêneros textuais no livro "Bem-vindo!"}

Apresentaremos, também, a análise de três atividades com gêneros textuais, retiradas da $8^{a}$ edição do livro "Bem-vindo!: a língua portuguesa no mundo da comunicação" (2016) - editora SBS. A escolha deste material foi devida a sua utilização no curso intensivo de PLE "Português com Torresmo", realizado no Instituto Federal do Sudeste de Minas Gerais campus Juiz de Fora, em junho/julho de 2016, no qual as autoras deste artigo puderam participar de sua elaboração e/ou atuando como docentes. $\mathrm{O}$ curso tinha o objetivo de ensinar português para estrangeiros que seriam voluntários nos Jogos Olímpicos no Rio de Janeiro no mesmo ano. No total, a instituição recebeu 13 alunos, em sua maioria, britânicos, os quais, além de terem $4 \mathrm{~h} /$ aula por dia durante 40 dias, participaram, também, de trabalhos voluntários nas cidades de Juiz de Fora e Maripá de Minas MG. O livro "Bem-vindo!" foi escolhido para trabalhar no "Português com Torresmo" devido a sua longa tradição no mercado, fácil acesso para compra e diversidade de temas e gêneros textuais.

Após o término do curso, foi possível notar que, assim como Tossati (2009) ressalta em sua dissertação de mestrado, esta obra traz muitas propostas diversificadas de gêneros, porém, em sua maioria, com foco na produção oral e compreensão auditiva. É perceptível que os autores se preocupam com a inserção dos gêneros textuais na obra, porém muitas atividades não contém uma sistematização funcional do uso do gênero em uma situação real. Neste artigo, analisaremos três atividades, relevando os seguintes aspectos: apresentação do gênero; questões linguísticas (escolhas lexicais e variação); meio de circulação; adequação espaço-temporal.

A figura 4 mostra duas atividades cujo propósito é ensinar ao aluno a recusar convites. O primeiro exercício tem foco na produção oral, apresentando ao aluno 4 situações interacionais, em que além de recusar, ele deve se desculpar por não aceitar o convite. A segunda atividade propõe a mesma ação comunicativa (recusar/desculpar-se), porém por meio de um gênero escrito, o e-mail: 


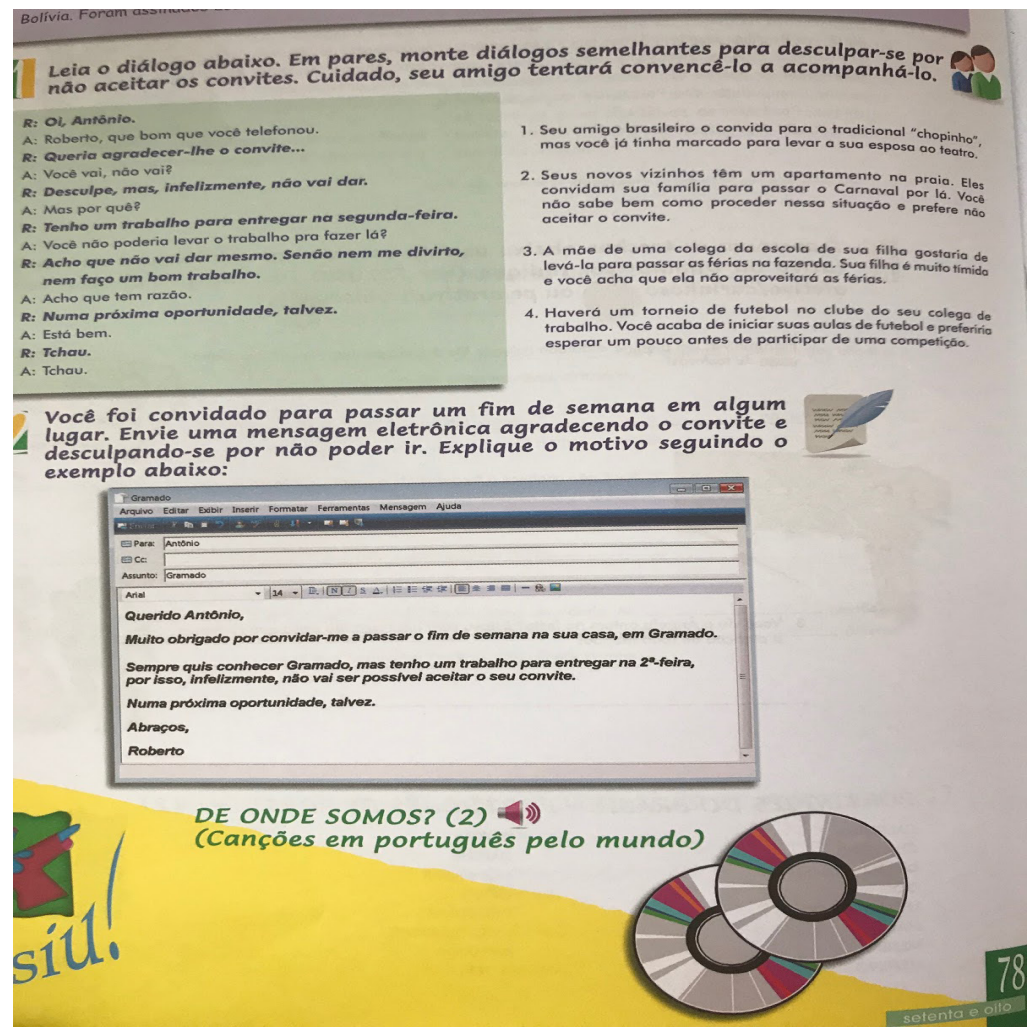

Figura 4

Fonte: Bem-vindo!: a língua portuguesa no mundo da comunicação (2016).

Esse exercício foi selecionado, pois traz um importante tópico a ser trabalhado em aulas de PLE: como recusar convites em português. Os exemplos trazidos pelas atividades mostram que a não aceitação de um convite em território brasileiro deve conter, obrigatoriamente, uma desculpa, uma justificativa plausível para que aquele que convida não fique chateado com a recusa. É rude dizer apenas "não, muito obrigada", já que o brasileiro é mais indiretivo em suas ações.

As situações propostas para um diálogo na primeira atividade são bastante interessantes e possíveis em contexto real, principalmente para os estrangeiros que terão uma longa estadia no Brasil. Para aqueles cuja estadia será curta, como no caso dos alunos do "Português para estrangeiros", a situação 1 seria de fácil ocorrência; a 2 e a 4 poderiam ser adapta- 
das pensando no contexto de voluntários temporários no Brasil.

Já a escrita do correio eletrônico também seria possível, no entanto, é possível dizer que, atualmente, é raro receber convites para viagens, passeios ou festas por este veículo. Redes sociais, como o Facebook, e aplicativos como o Whatsapp, que fornecem ambientes de troca de mensagens instantâneas, são os veículos mais utilizados para fazer convites, principalmente entre jovens e adultos. Por ser uma edição de 2016, os autores poderiam ter considerado inserir o gênero textual escrito "convite" por meio destes ambientes de interação mais utilizados na atualidade.

Outra questão que pode ser ressaltada é o fato de não ter sido trabalhado, de maneira estruturada, os recursos linguísticos de que o aluno deve lançar mão, nem em momento anterior nem em momento posterior aos exercícios. Os autores dão os exemplos e pedem para que o aluno faça de acordo com o mesmo, a atividade. Logo, cabe ao professor apresentar e sistematizar as escolhas lexicais apropriadas, tanto para as situações orais quanto para o e-mail.

Notou-se que o e-mail traz tanto o registro formal quanto o informal da língua, o que pode confundir o aluno. O texto inicia-se com "Querido Antônio" e termina com "Abraços", sugerindo proximidade, amizade. Porém, a linguagem utilizada no corpo do texto é bastante formal, não condizente com uma interação entre amigos. Logo, seria relevante mostrar ao aluno que a interação com um amigo pede uma linguagem mais informal, para não demonstrar distanciamento. As interações revelam sutilezas linguísticas que são o reflexo de nossa cultura e da maneira como agimos socialmente, as quais são extremamente importantes para evitar mal-entendidos; é, portanto, essencial que tais detalhes na produção escrita ou oral sejam ensinados ao aluno de PLE.

A segunda atividade escolhida para análise se encontra na figura 5 (p. 99), na qual os autores descrevem uma situação-problema e pedem para que o aluno escreva uma carta de reclamação de um produto com defeito para um gerente de supermercado. 


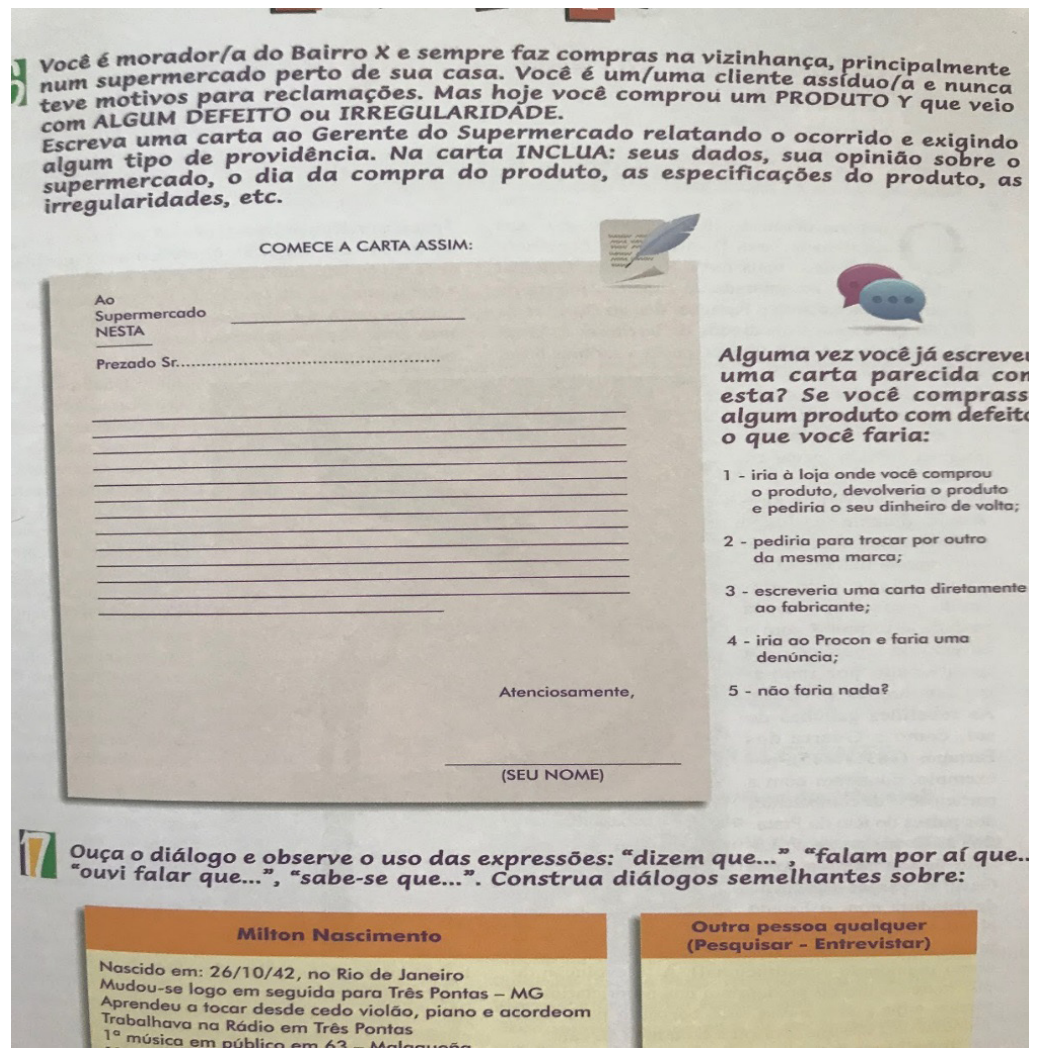

Figura 5

Fonte: Bem-vindo!: a língua portuguesa no mundo da comunicação (2016).

O exercício está inserido na unidade 10, intitulada "O Bairro", cuja intenção aparente é apresentar ao estrangeiro a divisão das cidades do Brasil em bairros e a cultura que se apresenta neles. Por isso, essa unidade foi escolhida para ser trabalhada no "Português com Torresmo", visto que os alunos iriam estar imersos no convívio de bairros de uma cidade de médio porte (Juiz de Fora-MG) e uma de grande porte (Rio de Janeiro-RJ), configurando relações interpessoais um pouco distintas. É muito comum que nos bairros de JF as pessoas se conheçam por décadas e construam uma relação quase familiar com seus vizinhos; já em cidades como o Rio de Janeiro, talvez isso não ocorra com tanta frequência.

A ação comunicativa de reclamar também é de extrema relevân- 
cia, pois é possível que o aluno se depare com o defeito de um produto, um serviço mal prestado ou um atendimento ruim. Portanto, o professor deve ensiná-lo estratégias de argumentação que façam com que ele atinja o objetivo de resolver o problema, evitando estresse por incompreensão linguística (visto que a situação de reclamar por si só já é bastante inconveniente).

Esta atividade também se encontra analisada na dissertação de Tossatti (2009, p. 59), em que ela observa "notamos que não há uma carta para ser lida como modelo, mas as condições de produção foram detalhadamente apresentadas. Essa atividade também é explorada para a produção oral, uma vez que, sobre a situação, são propostas ao aluno algumas perguntas". Concordamos com as palavras da autora, uma vez que não há o modelo e também não há um trabalho anterior expondo a estrutura do gênero carta de reclamação, não há apresentação e sistematização dos recursos discursivos da argumentação, sequer um trabalho de escolhas lexicais. A atividade surge, de repente, no meio da unidade, que não trabalha nenhum dos recursos necessários para ensinar/aprender o gênero.

Também observamos que este gênero pode estar ultrapassado, já que, atualmente, os principais meios de reclamação são: plataformas presentes em sites do tipo "Reclame aqui" (https://www.reclameaqui.com. br/); o PROCON, com atendimento presencial; ligações para centrais de reclamação da empresa, entre outros. Mais uma vez, ressaltamos que a edição do livro "Bem-vindo!", analisada neste artigo, é de 2016; portanto, a atividade poderia ter sido modificada, apresentando os gêneros e os meios de veiculação de uma reclamação mais utilizados atualmente.

\section{Conclusão}

Os livros didáticos, vistos como um dos principais meios pelo qual professores e alunos têm acesso ao conhecimento teórico, devem ser tidos como mediadores das interações entre os textos e os estudantes. Espera-se, deste modo, que esse material trabalhe com conteúdos gramaticais de forma contextualizada, a fim de que o aluno possa ter contato com situações de uso reais da língua-alvo. Para que as situações concretas do cotidiano desses estudantes possam ser trabalhadas dentro de sala, e, com isso, para que a especificidades deles possam ser atendidas, defendemos a exploração dos gêneros textuais durante o processo de aprendizado em sala de aula. Além disso, acreditamos que a utilização de um material didático que ofereça mais oportunidades de emprego dos gêneros contribui 
para que o estudante compreenda e saiba produzir os textos desses gêneros de forma eficaz, autônoma e consciente.

Através da análise das atividades, notamos que houve uma preocupação por parte da autora da apostila de PLE em explorar gêneros diversos com os quais os alunos têm ou terão contato em algum momento de suas vidas. Isso mostra que, em materiais didáticos como esse, os gêneros textuais estão deixando de ser somente aporte teórico (tema de reflexões teóricas) acerca do ensino de língua para se tornarem prática na vida dos estudantes e dos professores.

De acordo com os resultados obtidos da análise dos exemplos de exercícios, foi possível verificar que, tanto na apostila quanto no livro, houve a exploração de diferentes propósitos comunicativos, e a preocupação de que diversas comunidades discursivas fossem atendidas. Percebe-se o visível interesse dos autores em trazer para o material didático situações reais variadas de uso da língua, a fim de que as necessidades dos estudantes pudessem ser atendidas a partir da exploração de uma gama variada de gêneros textuais. No entanto, no livro "Bem-vindo!", é perceptível a necessidade de se estruturar melhor as atividades, de forma que o gênero não fique apresentado aleatoriamente no meio de uma unidade do livro, sem uma sequência didática que aborde os recursos linguísticos e os aspectos discursivos, culturais e sociais imbricados na estrutura e no uso de determinado gênero textual. Assim, concluímos que os autores de materiais didáticos devem estar atentos ao inserirem os gêneros textuais em suas obras, para que eles sejam ensinados/aprendidos de maneira coerente, levando-se em consideração toda a complexidade linguística, cultural e social presente em sua produção e circulação. 


\section{GENRES AS RECURRENT ACTIONS: analysis of teaching materials of Portuguese as a foreign language}

\section{ABSTRACT}

This paper aims to analyze the way that text genres are explored in two different teaching materials prepared for specific publics. The first material analyzed was elaborated by the author Denise Barros Weiss, professor at the Universidade Federal de Juiz de Fora, and it was used in a Portuguese as a Foreign Language course for intermediate students. The second material analyzed was used in another Portuguese as a Foreign Language course which happened at Instituto Federal de Educação, Ciência e Tecnologia do Sudeste de Minas Gerais (IF Sudeste) in 2016. It was used the definition of genres as typified and recurrent social actions, which was sustained by Miller (1984) and Bazerman (1994). Furthermore, the definition of text sustained by Bronckart (2012) and the notions of "communicative purpose" and "discourse community" elaborated by Swales (1990) were the basis for the analysis of the data. The concepts were used in order to enlighten the way as we analyse the examples of activities. Therefore we intend with this work to demonstrate that, through the exploration of diverse text genres, the social roles and the actions performed by the speakers are emphasized during the teaching of a foreign language.

KEYWORDS: Genre. Social Action. Portuguese as a Foreign Language. Teaching Material.

\section{REFERÊNCIAS}

BAZERMAN, C. Systems of Genres and the Enactement of social Intentions. In: FREEDMAN, A.; MEDWAY, P. Genre and the New Rhetoric. London: Taylor \& Francis, 1994, p. 79-101.

. Atos de fala, gêneros textuais e sistemas de atividades como os textos organizam atividades e pessoas. In: BAZERMAN, C. Gêneros textuais, ti- 
pificação e interação. Organização de Ângela Paiva Dionísio e Judith Chambliss Hoffnagel. São Paulo: Cortez, 2005, p. 32.

BRONCKART, J.P. Atividade de linguagem, textos e discursos: por um interacionismo sócio-discursivo. 2.ed. São Paulo: EDUC, 2012, p. 137-216.

CARVALHO, G. Gênero como ação social em Miller e Bazerman: O conceito, uma sugestão metodológica e um exemplo. In: MEURER, J.L.; BONINI, A; MOTTA-ROTH, D. Gêneros: teoria, métodos e debates. São Paulo: Parábola, 2005, p.130-149.

MARCUSCHI, L. A. Produção textual, análise de gêneros e compreensão. São Paulo: Parábola Editorial, 2008.

MILLER, C. R. Genre as social action. Quarterly Journal of Speech, n. 70, 1984, p. 151-167.

Rhetorical Community: The Cultural Basis of Genre. In: FREEDMAN, A.; MEDWAY, P. (eds). Genre and the New Rhetoric. London: Taylor \& Francis, 1994.

PONCE, M. H. DE.; BURIM, S. A.; FLORISSI, S. Bem-vindo!: a língua portuguesa no mundo da comunicação. 8. ed. São Paulo: SBS, 2016.

TOSATTI, N. M. Gêneros textuais em livros didáticos para ensino de Português para Estrangeiros: ocorrência e funcionalidade. In: SILEL: Simpósio Nacional e Internacional de Letras e Linguística. v. 1. Uberlândia: EDUFU, 2009.

Avaliação de proficiência escrita por meio da produção de gêneros textuais: uma análise do exame Celpe-Bras. Revista ContraPonto, Belo Horizonte, v.5, n. 8, p. 31-40, 2º sem. 2015.

SILVA, M. C. A noção de gênero em Swales: revisitando conceitos. Recorte Revista de Linguagem, Cultura e Discurso, Universidade Vale do Rio Verde, n.3, jul./ dez. 2005.

SOUZA, C. F. Memes: formações discursivas que ecoam no ciberespaço. Vértices, Campos dos Goytacazes, v. 15, n. 1, 2013.

SWALES, J. M. Genre analysis: English in academic and research settings. Cambridge: Cambridge University Press, 1990.

WEISS, D. B. Português para Estrangeiros II. Universidade Federal de Juiz de Fora, 2015.

Recebido: 30/04/2018

Aceito: 14/09/2018 